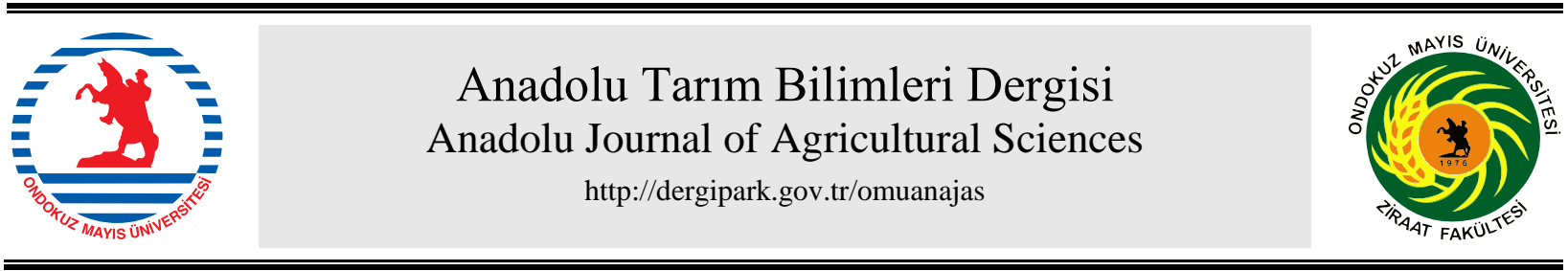

Araştırma/Research

\section{Karpuzda (Citrullus lanatus) meyve kalitesi ve aroma özellikleri üzerine anaçların \\ etkisi}

Anadolu Tarım Bilim. Derg./Anadolu J Agr Sci, 33 (2018) ISSN: 1308-8750 (Print) 1308-8769 (Online) doi: 10.7161/omuanajas.381414

\author{
Onur Karaağaça*, Ahmet Balkaya ${ }^{\mathrm{b}}$, Nesibe Ebru Kafkas ${ }^{\mathrm{c}}$ \\ aTartm ve Kırsal Kalkinmayı Destekleme Kurumu, Amasya \\ ${ }^{b}$ Ondokuz Mayls Üniversitesi, Ziraat Fakültesi Bahçe Bitkileri Bölümü, Samsun \\ ${ }^{c}$ Çukurova Üniversitesi, Ziraat Fakültesi Bahçe Bitkileri Bölümü, Adana \\ *Sorumlu yazar/corresponding author: onurkaraagac@gmail.com
}

Geliş/Received 19/01/2018～Kabul/Accepted 09/03/2018

\begin{abstract}
ÖZET
Aşılı karpuz fidesi kullanımı, stres koşullarına tolerans sağlaması ve verim potansiyelini olumlu yönde etkilemesi nedeniyle son yıllarda hızla artmaya başlamıştır. Sebzelerde aşılamada, kullanılan anaçlara bağlı olarak, meyve kalitesinde olumlu ya da olumsuz değişimler meydana gelebilmektedir. Bu amaca yönelik olarak yapılan araştırma sayısı ise sınırlı düzeydedir. Aşılı karpuz üretiminde, anacın meyve kalitesi üzerine etkisi tam olarak ortaya konulmamıştır. Bu çalışmada, karpuz anaç islah programında yer alan saf hat (bir adet Cucurbita moschata ve dört adet Cucurbita maxima) ve türler arası melez (beş adet C. maxima $\times$ C. moschata) kabak anaç genotiplerinin karpuzun kalite ve aroma içeriklerine etkisi incelenmiștir. Kontrol olarak aşısız Crisby $F_{1}$ karpuz çeşidi, bir adet su kabağı anacı (Argentario $F_{1}$ ) ve iki adet türler arası ticari hibrit anaç $\left(\mathrm{Obez} \mathrm{F}_{1}\right.$, Shintosa $\mathrm{F}_{1}$ ) kullanılmıştır. Tüm aşılı karpuzlarda; meyve eti, aşısız karpuza $(10.73 \mathrm{~N})$ göre daha sert olarak bulunmuştur. Anaç x kalem kombinasyonlarında meyve eti sertlik değerleri $13.75 \mathrm{~N}(\mathrm{~K} 6 / \mathrm{C})$ ve $22.53 \mathrm{~N}(\mathrm{M} 6 / \mathrm{C})$ ve meyve kabuk kalınlığı değerleri 16.05 (K9/C) - $18.24 \mathrm{~mm}$ (Argentario/C) arasında değişim göstermiştir. Aşılı kombinasyonların büyük bir bölümünde meyve kabuk kalınlığı değerleri artmıştır. Kullanılan farklı anaçların, karpuzun meyve şekline etki etmediği tespit edilmiştir. Çalışmada bir anaç kombinasyonu hariç, tüm kombinasyonlarda aşısız karpuza göre daha yüksek suda çözünebilir kuru maddenin (\% SÇKM) olduğu belirlenmiştir. En yüksek SÇKM oranı, M6/C (\% 12.87), M3/C (\% 12.53) ve B1/C (\% 12.50) kombinasyonlarında ölçülmüştür. Kullanılan anaca göre, $\mathrm{C}$ vitamini değerleri belirgin olarak değişmiştir. Aşılı karpuzlarda bu içerik; aşısız karpuza göre, \% 30.30 azalış (M3/C) ile \% 17.09 (Argentario/C) artış göstermiştir. İncelenen anaç/kalem kombinasyonlarının; 8 tanesinin aşısız Crisby $F_{1}$ karpuz çeşidinden daha yüksek ve 4 tanesinin ise daha düşük likopen içerdiği tespit edilmiştir. Tat analizi sonucunda; M2/C (4.87), M3/C (4.53), B1/C (4.35), Argentario/C (4.29) ve Obez/C (4.14) kombinasyonlarının aşısız karpuza göre (4.08) daha yüksek puan aldıkları belirlenmiştir. Ancak, incelenen anaç/kalem kombinasyonlarının büyük bir kısmında (9 adet) hafif derecede lifli yapının oluştuğu saptanmıştır. Karpuzda anaç kullanımının, uçucu aroma bileşiklerinin miktarı üzerine etkili olduğu belirlenmiştir. Belirlenen bileşikler arasında (Z,Z)-3,6nonadien-1-ol (karpuz kokusu) bileşiği yönünden yüksek ve (Z)-6-nonen-1-ol (kabak kokusu) bileşiği yönünden düşük değerlere sahip M6/C kombinasyonu ön plana çıkmıştır. Tüm kalite ve aroma sonuçları birlikte değerlendirildiğinde; M6 ve M2 anaç genotiplerinin aşılı karpuz için en iyi yerli anaç adayları olduğu belirlenmiştir.
\end{abstract}

\section{Effect of rootstocks on fruit quality and aroma characteristics of watermelon (Citrullus} lanatus)

\section{ABSTRACT}

In recent years, grafted watermelon seedling use has been rapidly increasing due to providing tolerance to stress conditions and positively affecting on yield potential. Fruit quality was varied depending on the rootstock used positively or negatively in grafted vegetables. The number of research is limited in this topic. The effect of the rootstocks on fruit quality has not been fully revealed in grafted watermelon production. In this study, the using of the inbred lines (one Cucurbita moschata and four Cucurbita maxima) and interspecific cross (five C. maxima $\times$ C. moschata) rootstocks were investigated for fruit
Anahtar Sözcükler:

Anaç 1slahı

Kışlık kabak

Meyve kalitesi

Karpuz

Aroma

Headspace/GC/MS 
quality and aroma characteristics on the watermelon. Non-grafted Crisby $\mathrm{F}_{1}$ watermelon cultivar, one Headspace/GC/MS bottle gourd (Argentario $F_{1}$ ) and two interspecific rootstock cultivars (Obez $F_{1}$, Shintosa $F_{1}$ ) were used as control commercial cultivars. In all grafted watermelon, the fruit flesh firmness was higher than nongrafted watermelon $(10.73 \mathrm{~N})$. According to the rootstock x scion combinations, the fruit firmness was varied between $13.75 \mathrm{~N}(\mathrm{~K} 6 / \mathrm{C})$ and $22.53 \mathrm{~N}(\mathrm{M} 6 / \mathrm{C})$. The rind thickness was changed between 16.05 (K9/C) - $18.24 \mathrm{~mm}$ (Argentario/C). In the most of the grafted combinations, the rind thickness increased. Rootstocks did not effect on fruit shape. Higher total soluble solids were determined in all graft combinations than non-grafted watermelon. The highest soluble solids contents were determined in the combination of $\mathrm{M} 6 / \mathrm{C}(12.87 \%), \mathrm{M} 3 / \mathrm{C}(12.53 \%)$ and $\mathrm{B} 1 / \mathrm{C}(12.50 \%)$. The vitamin $\mathrm{C}$ contents were significantly affected by rootstocks. These values in grafted watermelons increased by $30.30 \%$ (M3/C) and $17.09 \%$ (Argentario/C) reduction was observed compared to non-grafted watermelon. The lycopene content of eight combinations were found higher and four of them less than non-grafted watermelon. As a result of degustation panel tests, it was determined that M2/C (4.87), M3/C (4.53), B1/C (4.35) Argentario/C (29.4) and Obez/C (4.14) combinations scores were higher than non-grafted watermelon (4.08). However, they were determined that the majority of combinations (9) have slightly fibrous flesh structure. The use of grafted watermelon was found to be effective on the amount of volatile aroma compounds. M6 / C combination having high (Z,Z)-3,6-nonadien-1-ol (watermelon smell) compound and low (Z)-6-nonen-1-ol (squash smell) compound values was come into prominence. According to evaluated all fruit quality and aroma results; M6 and M2 genotypes were selected as the suitable local rootstock candidates for grafted watermelon production.

\section{Giriş}

Kalite genel olarak; bir üründe tüketicinin değer verdiği özelliklerin bir arada olma derecesini ifade etmektedir (Balkaya ve Özcan, 1997). Gerek dünyada ve gerekse ülkemizde sebzelerde kalite standartları daha çok ürünün dış görünüşüne göre yapılmaktadır. Örneğin, ülkemizde Türk Standartları Enstitüsü (TSE) standartlarına göre karpuzun 1. sınıf ürün olabilmesi için meyvenin; çeşide özgü renk ve şeklini alması, hafif iyileşmiş çatlak ya da hafif renk bozukluğu dişında kabuk kusurunun bulunmamış olması yeterlidir. Sebzelerin, tüketiciler tarafından kabul edilebilirliğini etkileyen çok sayıda kalite kriteri bulunmaktadır. Leonardi ve ark. (2017), sebzelerde kalite özelliklerini; görünüş (irilik, şekil, renk, dış kusur), tekstür, organoleptik özellikler (tat ve aroma) ve fonksiyonel özellikler (karotenoidler, vitaminler, fenolik bileşikler ve mineraller) olmak üzere dört ana gruba ayırmışlardır.

Son yüzyılda bitki çeşit ıslahı çalışmalarının ana hedefi; üreticinin birim alandan daha fazla gelir elde edebilmesi ve giderek artan tüketim talebinin karşılanabilmesi amacıyla verim unsurlarının arttırılması üzerine olmuştur. Çeşit ıslah programlarında, ticari kaygıdan dolayı, tat, aroma, besin içeriği gibi kalite özellikleri büyük ölçüde yer almamış ve genelde kalite kriterleri göz ardı edilmiştir. Türkiye de dâhil olmak üzere pek çok ülkede, belirtilen çeşit 1slah çalışmaları kapsamında geliştirilen verim potansiyeli yüksek ancak daha az lezzetli ve besin değeri düşük ticari çeşitlere karşı, zamanla tüketiciler tarafindan önemli düzeylerde olumsuz tepkiler oluşmuştur. Bunun sonucunda özellikle son yıllarda, alım gücünün ve sağlık bilincinin artması ile birlikte tüketiciler; antioksidanlar ve vitamin içeriği yüksek fonksiyonel özelliklere sahip sebze tür ve çeşitlerini daha fazla talep etmeye başlamıştır. Bu nedenle, karpuz gibi meyvesi yenilen sebzelerde de kalite ıslahına verilen önem artmış ve buna yönelik olarakta ıslah programlarının sayıları artmaya başlanmıştır.

Karpuzda suda çözünebilir kuru madde (SÇKM) içeriği, tadı etkileyen en önemli kalite kriterlerinden birisidir. Karpuz ıslahçıları uzun yıllardır SÇKM oranı yüksek olan hibrit karpuz çeşitlerini geliştirmeye çalışmışlardır (Gusmini ve Wehner, 2005a). Sebzeler içerisinde, en önemli karotenoidlerden olan likopen, en fazla karpuzda bulunmaktadır. Yapılan çalışmalar sonucunda; likopenin sadece renk yönünden çekicilik kazandırmadığı, ayrıca beslenme ve sağlık üzerine de yararlı etkilerinin olduğu belirlenmiştir (Perkins-Veazie ve Collins, 2004; Collins ve Perkins-Veazie, 2006; Perkins-Veazie ve ark., 2006). Karpuz, C vitamini içeriği yönünden de; lahanagiller, biber ve domatesten sonra en zengin sebze türleri içerisinde yer almaktadır (USDA, 2017). Karpuz çiğ olarak ve diğer sebzelere göre hacmen daha fazla tüketilmesi nedeniyle $\mathrm{C}$ vitamini bakımından oldukça değerli bir sebzedir. Karpuzda kaliteyi oluşturan en önemli unsurlardan biri de aromadır. Farklı bileşiklerden oluşan aroma, gıdaların duyusal özelliklerini belirleyen önemli bir kalite ölçütüdür. Karpuz meyvelerinde bulunan ve tadı etkileyen aroma bileşikleri aldehit, alkol, keton ve furan grupları içerisinde yer almaktadır (Beaulieu ve Lea, 2006).

Ülkemizde aş11 karpuz fidesi kullanımı avantajlarından dolayı son yıllarda büyük artış göstermiştir. 2015 yılı itibariyle üretilen karpuz fidelerinin yaklaşık \%90'ı aşılı olarak üretilmiştir (Yetişir, 2017). Son yıllarda sebzelerde aş1lı fide kullanımının yaygınlaşmasıyla birlikte, verim artışı ve birçok olumsuz stres faktörlerine dayanım yönünden önemli avantajlar elde edilmiştir. Aş̧1ı fide kullanımı ile karpuz çeşit 1slahı programları kapsamında toprak kökenli hastalık ve zararlılar gibi birçok seleksiyon 
kriteri göz ardı edilmeye başlanmıştır. Diğer taraftan, aşılı fide üretiminde kullanılan anacın kalite üzerine olan etkileri de tartışılmaya başlanmıştır. Birçok çalışmada, anacın kalite üzerine etkisinin olup olmadığı konusunda araştırıcılar arasında ortak bir fikir birlikteliği bulunmamaktadır. Bu farklılıklar; çevre, yetiştirme tekniği ve kullanılan farklı anaç kalem kombinasyonundan kaynaklanabilmektedir (Davis ve ark., 2008b; Rouphael ve ark., 2010; Balkaya, 2013; Guler ve ark., 2014). Ülkemizde özellikle son yıllarda aşılı karpuzların, meyve kalitesinin düşük ve sağlıksız olduğu yönünde bilimsel veriye dayanmayan spekülatif görüşler bulunmakta ve basında oldukça fazla yer almaktadır.

Ülkemizde karpuz için yerli bal ve kestane kabağ anacı geliştirme çalışmaları; 2005 yılından itibaren 1040144 numaralı TÜBİTAK projesinden elde edilen yerel genetik kaynakların bu amaca yönelik seleksiyonu ile başlamıştır (Balkaya ve ark., 2008). Karpuza anaç olarak geliştirilen saf hat ve türler arası melezler; verim, biyotik streslere dayanım ve aşı uyuşumu yönünden değerlendirilmiştir (Karaağaç, 2013). Ülkemizde aş11 karpuz kullanımının meyve kalitesi ve aroma miktarları üzerine etkilerinin belirlenmesine yönelik çalışma sayısı yok denecek kadar azdır. Bu çalışmada, yerli kabak anaç çeşit ıslah programı kapsamında geliştirilen anaç adaylarının karpuzun meyve kalitesi üzerine olan etkilerinin ayrıntılı olarak belirlenmesi ve kalite açısından en uygun anaçların tespit edilmesi amaçlanmıştır.

\section{Materyal ve Yöntem}

$\mathrm{Bu}$ çalışma; Samsun Karadeniz Tarımsal Araştırma Enstitüsü sera ve arazisinde, Ondokuz Mayıs
Üniversitesi Ziraat Fakültesi Bahçe Bitkileri Bölümü uygulama laboratuvarlarında ve Çukurova Üniversitesi Biyoteknoloji Araştırma ve Uygulama Merkezinde yürütülmüştür.

\subsection{Materyal}

Çalışmada anaç olarak; Fusarium oxysporum f. sp. niveum etmenine dayanıklı (Karaağaç, 2013), aşı başarı oranı yüksek (Karaağaç ve Balkaya, 2016), türler arası melezlenebilirlik (Karaağaç ve Balkaya, 2013) ve vejetatif büyüme durumu (Karaağaç, 2013) yönünden seleksiyon sslahı ile seçilmiş olan 10 kabak anaç adayı kullanılmıştır (Çizelge 1).

\subsection{Metot}

Yumurta tavuklarının canlı ağırlık değişimleri, yem Çalışmada kalem olarak kullanılan Crisby $F_{1}$ karpuz çeşidinin tohumları 15.04.2011 tarihinde, anaç tohumları ise bir hafta sonra torf: perlit (3:1) ortamı bulunan viyollere ekilmiş̧ir. Aşılama işlemi, eğimli kesik aşı yöntemi (Davis ve ark., 2008b) kullanılarak 29.04.2011 tarihinde tarafımızca gerçekleştirilmiştir. Deneme alanına $\left(41^{\circ} 14^{\prime} 02.31 \mathrm{~N}\right.$ ve $\left.36^{\circ} 29^{\prime} 21.63 \mathrm{E}\right)$ ait toprak analiz sonuçlarına göre $15 \mathrm{~kg}^{-d a^{-1}} \mathrm{P}_{2} \mathrm{O}_{5}, \quad 30 \mathrm{~kg} . \mathrm{da}^{-}$ ${ }^{1} \mathrm{~K}_{2} \mathrm{SO}_{4}$ ve $50 \mathrm{~kg} \cdot \mathrm{da}^{-1} \mathrm{Ca}\left(\mathrm{NO}_{3}\right)_{2}$ taban gübresi verilmiştir. Deneme, tesadüf blokları deneme desenine göre 4 tekerrürlü ve her parselde 10 bitki olacak şekilde kurulmuştur. Aşılı ve aşısız fideler $3.0 \times 1.0 \mathrm{~m}$ sıra arası ve sira üzeri mesafeyle 15.05.2011 tarihinde dikilmişlerdir. $\mathrm{Bu}$ aşamadan sonra biyotik stres etmenleriyle kimyasal mücadele yapılmış ve gerekli besin element takviyeleri düzenli olarak verilmiştir.

Çizelge 1. Çalışmada kullanılan anaç ve kalem materyaller

\begin{tabular}{|c|c|c|}
\hline Tür (Anaç ve kalem) & Kod / Çeşit & Generasyon \\
\hline C. moschata & B1 & $\mathrm{S}_{4}$ \\
\hline \multirow{4}{*}{ C. maxima } & K6 & $\mathrm{S}_{6}$ \\
\hline & K9 & $\mathrm{S}_{5}$ \\
\hline & K10 & $\mathrm{S}_{4}$ \\
\hline & K11 & $\mathrm{S}_{6}$ \\
\hline \multirow{5}{*}{ C. maxima x C. moschata } & M2 & $\mathrm{F}_{1}(\mathrm{~K} 11 \times \mathrm{B} 8)$ \\
\hline & M3 & $\mathrm{F}_{1}(\mathrm{~K} 9 \times \mathrm{B} 8)$ \\
\hline & M5 & $\mathrm{F}_{1}(\mathrm{~K} 12 \times \mathrm{B} 8)$ \\
\hline & M6 & $\mathrm{F}_{1}(\mathrm{~K} 4 \times \mathrm{B} 8)$ \\
\hline & M7 & $\mathrm{F}_{1}(\mathrm{~K} 2 \times \mathrm{B} 10)$ \\
\hline \multicolumn{3}{|l|}{ Anaç çeşitler (Kontrol) } \\
\hline \multirow[t]{2}{*}{ C. maxima x C. moschata } & Obez & $\mathrm{F}_{1}$ (Nickerson-Zwaan, Hollanda) \\
\hline & Shintosa & $\mathrm{F}_{1}$ (Fito, İspanya) \\
\hline Lagenaria siceraria & Argentario & $\mathrm{F}_{1}$ (Syngenta, İsviçre) \\
\hline C. lanatus (kalem) & Crisby & $F_{1}$ (Nunhems, Hollanda) \\
\hline
\end{tabular}

B: Bal kabağı, K: Kestane Kabağı, M: Türler arası melez (C. maxima $\times$ C. moschata) 
Meyve hasatları, $20.07-10.08 .2011$ tarihleri arasında tamamlanmıştır. Çalışmada aşağıda belirtilen meyve kalite ve aroma özellikleri incelenmiştir.

Meyve kabuk kalınlığ $1(\mathrm{~mm})$ : Her meyvenin üç farklı yerinden dijital kumpas ile ölçüm yapılarak tespit Meyvede kuru madde (\%): Meyvenin farklı iki yerinden alınan $125 \mathrm{~cm}^{3}$ hacimli küp şeklindeki meyve eti örnekleri kullanılmışıır (Bruton ve ark. 2009). Analiz için her kombinasyona ait 20 meyveden elde edilen 40 adet meyve örneğinin taze ağırlıkları alındıktan sonra etüvde $80{ }^{\circ} \mathrm{C}$ sicaklıkta 72 saat süreyle bekletilmiştir. Süre sonunda örneklerin ağılıklarının stabil olup olmadıkları kontrol edilerek kurutma işlemine son verilmiştir.

Meyve eti sertliği $(\mathrm{N})$ : Her kombinasyona ait 20 meyvede, ekvatoral ve dış bölgelerden alınan küp şeklinde iki örnek $\left(125 \mathrm{~cm}^{3}\right)$ kullanılmıştır (Bruton ve ark., 2009). Meyve eti sertliğinin tespit edilmesinde 8.0 $\mathrm{mm}$ uca sahip penetrometreden faydalanılmıştır. Her küpün karşı kenarlarından ikişer kez penetrometre ile meyve eti sertliği belirlenmiştir.

Suda çözünebilir kuru madde (SÇKM) (\%): Analiz için örnekler Bruton ve ark. (2009)'a göre hazırlanmıştır. Her kombinasyona ait 20 meyveden elde edilen 40 adet meyve örneğinin suyu çıkarılmıştır. SÇKM değerinin ölçülmesinde el refraktometresi kullanılmıştır.

Meyve et rengi: Minolta CR-410 dijital renk ölçer aleti kullanılarak belirlenmiştir. Renk ölçümü CIE $\mathrm{L} * a * b *$ renk sinıflandırma sistemine göre yapılmıştır. Renk ölçümüne başlanmadan önce tam beyaz renkteki tabla $\left(L^{*}=97.70, a^{*}=-0.48, b^{*}=2.23\right)$ kullanılarak cihazın kalibrasyonu yapılmıştır (Perkins-Veazie ve Collins, 2004). Renk okuması, her kombinasyona ait 20 meyvede yapılmıştır. Her meyvede orta, alt, üst ve kenar kısımlarından olmak üzere toplam dört adet okuma yapılarak ortalamaları alınmıştır (Tlili ve ark., 2011). " $\mathrm{L} *$ ", 0-100 birimleri arasında rengin parlaklık değerini, "a*", yeşil tonları (-) ve kırmızı tonları $(+)$ arasındaki renk değerini ve " $\mathrm{b}$ *" ise sarı tonları $(+)$ ile mavi tonları (-) arasındaki renk değerini belirtmektedir. Ayrıca a* ve $b^{*}$ verilerini kullanarak hue $\left(\mathrm{H}^{\circ}\right)$ ve chroma $\left(\mathrm{C}^{*}\right)$ değerleri de bulunmuştur. Hue değeri, trigonometrik düzlemde gerçek renk değerini belirtmekte olup $0^{\circ}-90^{\circ}$ arası kırmızı-mor tonları ifade etmektedir. Chroma ise rengin yoğunluğunun sayısal olarak tespit edilmesinde kullanılmaktadır. $\mathrm{H}^{\circ}$ ve $\mathrm{C}^{*}$ değerleri, aşağıdaki denklemlerin uygulanması ile elde edilmiştir (Saftner ve ark., 2007).

$$
H^{\circ}=\tan ^{-1}(b / a) \quad C^{*}=\sqrt{a^{2}+b^{2}}
$$

C vitamini $\left(\mathrm{mg} 100 \mathrm{~g}^{-1}\right)$ : Yüksek performanslı sıvı kromatografi (HPLC) cihazı (Agilent Technologies 1100) kullanılarak, Bozan ve ark. (1996)'nın geliştirmiş olduğu tekniğe göre belirlenmiştir. Ekstraksiyonda metafosforik asit kullanılmıştır. Veriler, $242 \mathrm{~nm}$ dalga boyunda HPLC/UV detektör kullanılarak tespit edilmiştir.

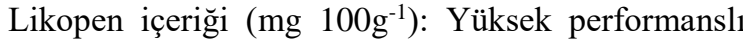
sivi kromatografi (HPLC) cihazı kullanılarak (Agilent Technologies 1100), Barua (2001)'nın uyguladığ edilmiş̧ir.

Meyve şekil indeksi: Parseldeki her bitkiden hasat edilen meyvelerin ekvatoral bölgelerinin çapı ile sap çukuru - çiçek burnu arasındaki mesafenin oranlanmasıyla belirlenmiştir.

metoda göre likopen analizleri yapılmıştır. Ekstraksiyon aşamasında $\quad 1.0 \mathrm{~g}$ meyve örneğine $0.6 \mathrm{~mL}$ tetrahydrofuran eklenmiştir. Elde edilen homojenat, iki dakika süre ile $1300 \mathrm{xg}$ hızında ve oda sıcaklığ koşullarında santrifüj edilmiştir. Elde edilen üst faz, turbo vap evaporator cihazı ile yaklaşı $2.5 \mathrm{ml}$ kalana kadar uçurulmuştur. Mobil faz olarak; acetonitrile: tetrahydrofuran: methanol: $\% 1$ amonyum asetat (65:25:6:4) kullanılmıştır. Örnekler 0.45 um filtreden geçirilerek HPLC cihazına enjekte edilmişlerdir. Akış hızı $0.5 \mathrm{ml} /$ dakika olmuştur. Analiz 15 dakika sürmüştür. Kolon olarak C18 kolonu kullanılmıştır. UV detektör ile $484 \mathrm{~nm}$ dalga boyunda okumalar yapılmıştır.

Duyusal analiz: Soteriou ve ark. (2016)'a göre yapılmıştır. Analizde her genotipe ait toplam dokuz meyve kullanılmıştır. Duyusal analizlerde yirmi kişi panelist olarak yer almıştır. Panelistler, karpuz tadına yönelik olarak 0 (çok kötü) - 5 (çok iyi) skalasını kullanmışlardır. Ayrıca panelistler, karpuzda kabak kokusu varlığı ve liflilik durumlarına yönelik olarak da değerlendirme yapmışlardır.

Aromatik bileşikler: Kafkas (2004) tarafından modifiye edilen headspace katı faz mikro ekstraksiyon (SPME) tekniği uygulanmıştır. Uçucu aroma bileşiklerinin belirlenmesinde Gaz Kromatografisi Kütle Spektrofotometresi (GC/MS) cihazı kullanılmıştır. Meyvenin farklı kısımlarından alınan $5.0 \mathrm{~g}$ meyve örneği cam tüp içerisine konulmuş ve $\mathrm{NaCl}$ solüsyonu eklenmiştir. Otosampler ünitesine yerleştirilen örneklerden; SPME katı faz mikro ekstraksiyon şırıngasıyla aroma maddeleri adsorbe edilmiş ve apolar kolonun kullanıldığı GC-MS cihazının enjektör kısmına desorbe edilmişlerdir. Örnekler, GC/MS cihazında 70 dakika bekletilmiştir. Tanımlama işlemleri, Wiley ve NIST Kütüphane Tarama Yazılımları kullanılarak gerçekleştirilmiştir (Shalit ve ark., 2001). Aroma maddelerinin tanısında GC/MS'de belirlenen piklerin kütle spektrumunun referans bileşiklerle veya bilgisayar hafızasındaki kütle spektrumlarıyla karşılaştırılması yoluyla yapılmıştır.

İstatistiksel analiz: Öncelikle verilerin normal dağılıma uygunluğunun tespiti için normalite testi yapılmıştır. Ardından \% değerler için arcsin transformasyonu ve " 0 " içeren veri setleri için ise karekök transformasyonu uygulanmıştır. Ardından veriler varyans analizine (ANOVA) tabi tutulmuştur. Duncan çoklu karşılaştırma testine göre $\% 0.5$ ya da $\% 0.1$ önemlilik sınırları üzerinde yer alan kombinasyonlar arasında harflendirme yapılmıştır. Deneme hatasının oranını gösteren doğruluk katsayıları (CV) hesaplanmıştır. 


\section{Bulgular ve Tartışma}

Aşısız ve aşılı kombinasyonlar arasında kabuk kalınlıkları yönünden istatistiksel olarak önemli bir farklılık bulunmamıştır. Kabuk kalınlığı değerleri, 16.05 (K9/C) - $18.24 \mathrm{~mm}$ (Argentario/C) arasında değişim göstermiştir. İstatitiksel olarak önemli bulunmamakla birlikte birçok anacın, meyve kabuk kalınlığını yaklaşık $1 \mathrm{~mm}$ seviyesinde arttırdığ 1 belirlenmiştir (Çizelge 2).

$\mathrm{Bu}$ konuda yapılan araştırma sonuçları incelendiğinde, elde edilen sonuçların farklılık gösterdikleri görülmüştür. Bazı çalışmalarda (Alan ve ark., 2007; Huitrón ve ark., 2007; Edelstein ve ark., 2014; Liu ve ark., 2017) karpuzdaki meyve kabuk kalınlığının, istatistiksel olarak anaç kullanımından dolayı önemli düzeyde etkilenmediği bildirilirken, diğer bazı çalışmalarda (Alexopoulos ve ark., 2007; Proietti ve ark., 2008; Karaca ve ark. 2012; Huang ve ark., 2016; Fredes ve ark., 2017) ise meyve kabuk kalınlığ 1 değerlerinin aşılamadan etkilendiği belirtilmiştir. Davis ve PerkinsVeazie (2005), Fita ve ark. (2007), Sakata ve ark. (2007) ve Bigdelo ve ark. (2017) tarafindan yapilan çalışmalarda, meyvelerdeki kabuk kalınlığının kullanılan anaca bağlı olarak değiştiği vurgulanmıştır. Davis ve ark. (2008a), bu durumun farklı ekolojik koşular altında ele alınan anaç/kalem kombinasyonu ve uygulanan kültürel işlemlerden kaynaklanabileceğini ifade etmişlerdir.

İncelenen genotiplerde, aşılama sonucunda; farklı kabak anaçlarının, meyve şekil indekslerine etkisi istatistiksel olarak önemsiz olduğu bulunmuştur. Meyve şekil indeksi değerleri, 0.88 ile 1.00 arasında değişim göstermiştir (Çizelge 2). Literatürde, aşılamanın karpuzun meyve şekil indeksini etkilemediği vurgulanmıştır (Davis ve Perkins-Veazie, 2005; Proietti ve ark., 2008; Rouphael ve ark., 2008; Bigdelo ve ark., 2017; Fredes ve ark., 2017; Soteriou ve ark., 2017). Karpuzda meyve şeklinin kalıtımının " $O$ " geni tarafindan kontrol edildiği bilinmektedir. " $O$ ” geni yönünden homozigot dominant bitkiler uzun, homozigot resesif bitkiler yuvarlak ve heterozigot bitkiler de oval şekilli olmaktadır. Meyve şekil indeksinin monogenik kalıtımlı olması nedeniyle, farklı ekolojik koşullardan çok fazla etkilenmemektedir (Gusmini ve Wehner, 2005b). Ancak bazı anaç $\times$ kalem kombinasyonlarında, aşı uyuşmazlığından dolayı meyve şeklinde bozulmalar olabileceği ve meyve şekil indeksinin de kısmen değişebileceği bildirilmiştir (Sakata ve ark., 2007; Davis ve ark., 2008a).

Çalışmada aşısız ve farklı anaçlara aşılı karpuz genotiplerinde, meyvede kuru madde içerikleri yönünden istatistiksel olarak önemli düzeyde herhangi bir farklılık olmadığ1 belirlenmiştir. Meyvede kuru madde içeriği, aşısız karpuzda ortalama \% 8.58, aşılı karpuzlarda ise $\% 9.0$ olarak tespit edilmiştir (Çizelge 2).

Meyvede kuru madde içeriği en fazla; M3/C (\%9.46), K11/C (\%9.39) ve M 6/C (\% 9.35) kombinasyonlarında tespit edilmiştir. $\mathrm{Bu}$ değer yönünden en düşük içerikli genotipler ise sirasiyla M7/C (\% 8.55) ve Shintosa/C (\% 8.58) olarak belirlenmiştir. Karpuz (Colla ve ark., 2006; Colla ve ark., 2007; Proietti ve ark., 2008; Rouphael ve ark., 2008; Petropulos ve ark., 2014) ve hiyar (Li ve ark., 2006; Huang ve ark., 2009; Rouphael ve ark., 2016) türlerinde yapılan birçok çalışmada, farklı anaçların ve aşılama işleminin meyvede kuru madde içeriği üzerine etkisinin önemli olmadığı tespit edilmiştir. Araştırma sonuçları belirtilen literatürlerle benzerlik göstermiştir.

Çizelge 2. Aşılı ve aşısız karpuzlara ait meyvelerde kabuk kalınlığı, şekil indeksi, kuru madde ve et sertliği değerleri

\begin{tabular}{|c|c|c|c|c|c|}
\hline Kombinasyonlar & $\begin{array}{l}\text { Kabuk kalınlığ } 1 \\
(\mathrm{~mm})\end{array}$ & $\begin{array}{l}\text { Meyve şekil } \\
\text { indeksi }\end{array}$ & Kuru madde $(\%)$ & \multicolumn{2}{|c|}{ Meyve eti sertliği (N) } \\
\hline $\mathrm{B} 1 / \mathrm{C}$ & 16.09 & 0.95 & 9.12 & 18.73 & $\mathrm{~cd}$ \\
\hline $\mathrm{K} 6 / \mathrm{C}$ & 17.90 & 0.96 & 9.28 & 13.75 & $\mathrm{~g}$ \\
\hline K9/C & 16.05 & 0.93 & 8.62 & 17.61 & ef \\
\hline $\mathrm{K} 10 / \mathrm{C}$ & 16.17 & 0.94 & 8.74 & 18.22 & de \\
\hline $\mathrm{K} 11 / \mathrm{C}$ & 17.45 & 0.91 & 9.39 & 17.75 & $\mathrm{e}$ \\
\hline $\mathrm{M} 2 / \mathrm{C}$ & 18.13 & 0.97 & 9.05 & 20.42 & $\mathrm{~b}$ \\
\hline $\mathrm{M} 3 / \mathrm{C}$ & 18.17 & 0.88 & 9.46 & 18.47 & de \\
\hline M5/C & 17.79 & 0.93 & 8.85 & 16.75 & $\mathrm{f}$ \\
\hline $\mathrm{M} 6 / \mathrm{C}$ & 17.55 & 0.98 & 9.35 & 22.53 & $\mathrm{a}$ \\
\hline $\mathrm{M} 7 / \mathrm{C}$ & 17.18 & 0.95 & 8.55 & 12.73 & $\mathrm{~h}$ \\
\hline Argentario/C & 18.24 & 0.98 & 9.05 & 20.46 & $\mathrm{~b}$ \\
\hline Obez/C & 17.48 & 0.93 & 8.92 & 18.96 & $\mathrm{~cd}$ \\
\hline Shintosa/C & 17.83 & 0.93 & 8.58 & 19.60 & $\mathrm{bc}$ \\
\hline $\mathrm{C}$ & 16.30 & 1.00 & 8.65 & 10.73 & $\mathrm{i}$ \\
\hline $\mathrm{P}$ & ÖD & ÖD & ÖD & \multicolumn{2}{|c|}{ ** } \\
\hline $\mathrm{CV}(\%)$ & 12.13 & 6.04 & 7.05 & \multicolumn{2}{|c|}{3.10} \\
\hline
\end{tabular}


Meyve eti sertliği, kalsiyum içeriği ile ilişkili bir karakterdir. Ancak su içeriği, transpirasyon, hücre adezyonu ve hücre duvarının yapısı da bu özelliği etkilemektedir (Saladié ve ark., 2007). İncelenen aşısız ve aşıll kombinasyonlarda meyve eti sertliğinde istatistiksel olarak önemli seviyede farklılıkların olduğu bulunmuştur. Tüm aşılı karpuzlarda meyve eti, aşısız karpuza $(10.73 \mathrm{~N})$ göre daha sert bulunmuştur (Çizelge 2). M6/C kombinasyonu en yüksek meyve et sertliği değeri $(22.53 \mathrm{~N})$ ile tek başına bir istatistiksel grup oluşturmuştur. Argentario/C (20.46 N) ve M2/C (20.42 $\mathrm{N})$ hibrit genotiplerinde de meyve eti sertliği yönünden yüksek değerler elde edilmiştir. Anaç olarak kestane kabaklarına aşılanan karpuzlarda meyve eti sertliği ortalama $16.83 \mathrm{~N}$ değeri ile diğer anaç gruplarına göre daha yumuşak meyve etine sahip olmuşlardır.

Birçok araştırma sonucu, aşılamanın genel olarak meyve eti sertliğini artırdığını göstermiştir (Taylor ve ark., 2006; Huitrón-Ramírez ve ark., 2009; Edelstein ve ark., 2014). Soteriou ve Kyriacou (2015), karpuzda anaç kullanımının meyve eti sertliğini ortalama \%44-55 oranında arttırdığını bildirmiştir. Meyve eti sert olan karpuzlarda iç boşalması daha geç olmakta ve daha uzun süre muhafaza edilebilmektedir (Arslan, 2010). Bu nedenle, birçok anaç $\times$ kalem kombinasyonunda meyve eti sertliğini artırması hem üreticiler ve hem de tüketiciler yönünden istenen bir özelliktir.

Karpuz islah programlarında en önemli seleksiyon kriterlerinden birisi de SÇKM oranıdır. Wehner (2008), ideal bir tat için karpuzda SÇKM oranının minimum \%10 olması gerektiğini bildirmiştir. Çalışmada incelenen tüm kombinasyonlarda SÇKM oranı \% 11'in üzerinde bulunmuştur. Kullanılan anaçlar, karpuzdaki SÇKM oranını istatistiksel olarak önemli düzeyde etkilemiştir.
Anaç/kalem kombinasyonlarında, M5/C ( $\%$ 11.0) kombinasyonu hariç tüm kombinasyonlarda aşısız karpuza göre daha fazla SÇKM değerleri elde edilmiştir. Aşılı karpuzlarda ortalama SÇKM \% 11.93 ve aşısız karpuzda ise \%11.27 olarak belirlenmiştir. (Çizelge 3). En yüksek SÇKM oranı, M6/C (\% 12.87), M3/C $\quad(\%$ 12.53) ve B1 (\% 12.5) kombinasyonlarından elde edilmiştir. Söz konusu anaçlar bu yönleriyle anaç sslah programında değerlendirilmektedir. Birçok araştırıcı; aş11 karpuzlarda, aşısız karpuzlara göre SÇKM oranının, \% 22.5 (Salam ve ark., 2002), \%6 (Arslan, 2010) ve \% 5.3 (Karaca ve ark., 2012) oranlarında daha fazla olduğunu bildirmişlerdir.

Elde ettiğimiz sonuçlar, bu çalışmalarla büyük oranda (M5/C hariç) uyum göstermektedir. Ancak birçok literatürde, aşısız ve aşılı karpuzlar arasında SÇKM değeri yönünden önemli derecede farklılığın olmadığı da bildirilmiştir (Miguel ve ark., 2004; Roberts ve ark., 2005; Taylor ve ark., 2006; Colla ve ark., 2007; Proietti ve ark., 2008; Bruton ve ark., 2009; Soteriou ve Kyriacou, 2015; Alan ve ark., 2017; Soteriou ve ark., 2017). Birçok araştırıcı; aşılı karpuzlarda SÇKM oranının kullanılan anaca bağlı olarak değişkenlik gösterdiğini belirtmişlerdir (Yetişir ve Sarı, 2003; Davis ve Perkins-Veazie 2005; Huitrón ve ark., 2007; Çandır ve ark., 2013; Oluk ve ark., 2017).

Yapılan çalışmalardan elde edilen sonuçların bu kadar değişkenlik göstermesi; SÇKM'nin poligenik bir karakter olması nedeniyle ekolojik koşullardan daha çok etkilenmesi (Gusmini ve Wehner, 2005b) ve anaç/kalem kombinasyonlarının uyum performanslarının farklılık göstermesinden kaynaklanabilir.

Çizelge 3. Aş̧1ı ve aşısız karpuzlara ait meyvelerde SÇKM, C vitamin, likopen değerleri ve duyusal analiz sonuçları

\begin{tabular}{|c|c|c|c|c|c|}
\hline Kombinasyonlar & SÇKM (\%) & 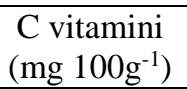 & 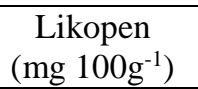 & Tat skalası & $\begin{array}{l}\text { Olumsuz } \\
\text { görüşler }\end{array}$ \\
\hline $\mathrm{B} 1 / \mathrm{C}$ & $12.50 \mathrm{ab}$ & $14.22 \mathrm{bc}$ & $6.7 \mathrm{ab}$ & $4.35 \mathrm{a}-\mathrm{c}$ & - \\
\hline $\mathrm{K} 6 / \mathrm{C}$ & $12.11 \mathrm{~b}-\mathrm{e}$ & 11.54 ef & $6.7 \mathrm{ab}$ & $3.50 \mathrm{f}$ & $\mathrm{KK}, \mathrm{HL}$ \\
\hline $\mathrm{K} 9 / \mathrm{C}$ & $12.17 \mathrm{~b}-\mathrm{d}$ & $12.83 \mathrm{~cd}$ & $5.7 \mathrm{~d}$ & $3.85 \mathrm{de}$ & $\mathrm{HL}$ \\
\hline $\mathrm{K} 10 / \mathrm{C}$ & $11.63 \mathrm{c}-\mathrm{e}$ & $11.75 \mathrm{e}$ & $5.8 \mathrm{~d}$ & 3.66 ef & HL \\
\hline $\mathrm{K} 11 / \mathrm{C}$ & $11.33 \mathrm{de}$ & $13.02 \mathrm{~b}-\mathrm{d}$ & $5.8 \mathrm{~d}$ & $3.85 \mathrm{de}$ & HL \\
\hline $\mathrm{M} 2 / \mathrm{C}$ & $12.15 \mathrm{~b}-\mathrm{e}$ & 13.14 b-d & $6.3 \mathrm{c}$ & $4.87 \mathrm{a}$ & - \\
\hline $\mathrm{M} 3 / \mathrm{C}$ & $12.53 \mathrm{ab}$ & $10.63 \mathrm{f}$ & $6.4 \mathrm{bc}$ & $4.53 \mathrm{ab}$ & HL \\
\hline $\mathrm{M} 5 / \mathrm{C}$ & $11.00 \mathrm{e}$ & $11.08 \mathrm{f}$ & $6.5 \mathrm{a}-\mathrm{c}$ & 3.94 c-e & HL \\
\hline M6/C & $12.87 \mathrm{a}$ & $12.25 \mathrm{~d}$ & $6.8 \mathrm{a}$ & $4.05 \mathrm{~b}-\mathrm{d}$ & - \\
\hline $\mathrm{M} 7 / \mathrm{C}$ & $11.63 \mathrm{c}-\mathrm{e}$ & $12.30 \mathrm{~d}$ & $6.3 \mathrm{c}$ & $3.47 \mathrm{f}$ & $\mathrm{KK}, \mathrm{YL}$ \\
\hline Argentario/C & 12.17 b-d & $15.25 \mathrm{a}$ & $5.2 \mathrm{e}$ & 4.29 a-d & HL \\
\hline Obez/C & 11.73 c-e & $14.47 \mathrm{~b}$ & $6.3 \mathrm{c}$ & 4.14 a-d & HL \\
\hline Shintosa/C & $11.33 \mathrm{de}$ & $14.20 \mathrm{bc}$ & $6.5 \mathrm{a}-\mathrm{c}$ & $3.93 \mathrm{c}-\mathrm{e}$ & HL \\
\hline $\mathrm{C}$ & $11.27 \mathrm{e}$ & $12.28 \mathrm{~d}$ & $6.3 \mathrm{c}$ & $4.08 \mathrm{~b}-\mathrm{d}$ & - \\
\hline $\mathrm{P}$ & $*$ & $* *$ & $* *$ & $* *$ & \\
\hline $\mathrm{CV}(\%)$ & 4.93 & 10.07 & 3.76 & 9.11 & \\
\hline
\end{tabular}

B: Bal kabağı, K: Kestane Kabağı, M: Türler arası melez (C. maxima $\times$ C. moschata), C: Aşısız Crisby F1, KK: Kabak Kokusu, HL: Hafif lif varlığı, YL: Yoğun lif varlı̆̆ 1 **: P>0.01; *: P>0.05 
Aşısız ve farklı kabak anaçlarına aşılı karpuz kombinasyonlar arasında, C vitaminin içeriği yönünden istatistiksel olarak önemli seviyede farklılıkların olduğu saptanmıştır. Aşısız karpuzun C vitamini içeriği, 12.28 mg $100 \mathrm{~g}^{-1}$ olarak belirlenmiştir. Aşılı karpuzlar ise aşısız karpuza göre, \%30.3 azalış (M3/C) ile \%17.09 (Argentario/C) artış arasında dağılış göstermiştir (Çizelge 3). Kabak anaçlarının 8 adedine ait aşılı karpuzlarda, aşısız karpuza göre $\mathrm{C}$ vitamini içeriği artarken, 5 anaç/kalem kombinasyonunda ise azalış olduğu tespit edilmiştir. Su kabağı anacı Argentario, C vitamini içeriğini en çok artıran anaç olarak belirlenmiştir (Çizelge 3). Yerel anaçlar arasında, B1 bal kabağı anacına aşılı karpuzlar $14.22 \mathrm{mg} 100 \mathrm{~g}^{-1}$ değeriyle

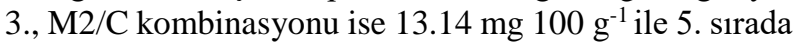
yer almışlardır. Karpuzun $\mathrm{C}$ vitamini içeriğini; Leskovar ve ark. (2004) 4.23-6.98 mg $100 \mathrm{~g}^{-1}$, Mélo ve ark. (2006) $57.62 \mathrm{mg} 100 \mathrm{~g}^{-1}$ ve Tlili ve ark. (2011) 10.5-23.9 mg $100 \mathrm{~g}^{-1}$ olarak tespit etmişlerdir.

Proietti ve ark. (2008), C. maxima $\times$ C. moschata anaçlarına aşılı karpuzda $C$ vitamini içeriğinin $\% 7.3$ oranında artış gösterdiğini bildirmişlerdir. Qin ve ark. (2014) karpuzda farklı anaç kalem kombinasyonlarında C vitamini içeriklerini inceledikleri çalışmada anaçlara göre artış veya azalışlar olduğunu bildirmişlerdir. Ayrıca hıyarda, aşılamanın $\mathrm{C}$ vitamini üzerine etkisinin olumlu olduğu tespit edilmiştir (Zhu ve ark., 2006; Huang ve ark., 2009).

Sebzeler arasında karpuz, en çok likopen içeren ürün olma özelliğini göstermektedir (USDA, 2017). Likopen içeriği; her ne kadar domates ile özdeşleştirilmiş olsa da karpuz, domatesten yaklaşık iki kat fazla likopen içeriğine sahiptir. Karpuzun içeriğinde bulunan toplam karotenoidlerin \% 92'si likopenden oluşmaktadır. Likopen içeriğinin fazla ve beta karoten içeriğinin düşük olmas1; meyvede kırmızı rengin, tam tersi durumda ise sarı ya da turuncu rengin ortaya çıkmasına katkı sağlamaktadır (Lewinsohn ve ark., 2005). Araştırma sonuçlarına göre, farklı anaç/kalem kombinasyonları arasında likopen içeriği yönünden istatistiksel olarak önemli düzeyde farklılıkların olduğu saptanmıştır. En yüksek likopen içeriği sırasıyla; M6/C (6.8 mg $\left.100 \mathrm{~g}^{-1}\right)$, B1/C (6.7 mg $\left.100 \mathrm{~g}^{-1}\right)$ ve K6/C (6.7 mg $\left.100 \mathrm{~g}^{-1}\right)$ kombinasyonlarında saptanmıştır (Çizelge 3). Argentario/C kombinasyonu (5.2 mg $100 \mathrm{~g}^{-1}$ ) ise likopen içeriği yönünden en son sırada yer almıştır. İncelenen anaç/kalem kombinasyonlarının; 8 tanesinin aşısız Crisby $F_{1}$ karpuz çeşidinden daha yüksek, 4 tanesinin ise daha düşük likopen içeriğine sahip oldukları tespit edilmiştir. Bir çok çalışmada, karpuzda aşılamanın likopen içeriğini olumlu yönde etkilediği bildirilmiştir (Davis ve Perkins-Veazie, 2005; Taylor ve ark., 2006; Davis ve ark., 2008a; Proietti ve ark., 2008; Kyriacou ve ark., 2016). Çandır ve ark. (2013), incelemiş oldukları karpuza aşılanan 21 adet su kabağı anacından, 13 tanesinde likopen içeriğinin artış gösterdiğini belirlemişlerdir. Anaç kullanımının karpuzdaki likopen içeriğine etkisinin incelendiği çalışmalarda; anaç $\times$ kalem $\times$ lokasyon $\times$ yıl interaksiyonlarına bağlı olarak farklı sonuçlar elde edilmiştir (Bruton ve ark., 2009; Kyriacou ve ark., 2016; Özdemir ve ark., 2016; Liu ve ark., 2017). Benzer şekilde, Bang ve ark. (2010) karpuzdaki likopen içeriğinin; çeşit, olgunluk durumu ve ekolojik koşullara göre değişiklik gösterdiğini bildirmişlerdir.

Panel testi puanları yönünden incelenen genotipler arasında istatistiksel olarak önemli düzeyde farklılıkların olduğu belirlenmiştir. Aşılı kombinasyonlar içerisinde $\mathrm{M} 2 / \mathrm{C}, \mathrm{M} 3 / \mathrm{C}$ ve B1/C kombinasyonları sirasiyla 4.87, 4.53 ve 4.35 puanları ile tat yönünden en beğenilen genotipler olmuşlardır (Çizelge 3). Duyusal analiz sonucunda, aşısız karpuz çeşidine ait meyvelere panelistler tarafindan ortalama 4.08 puan verilmiştir. İncelenen anaçların kullanıldığı kombinasyonların; 5 tanesinin tat puanları, aşısız karpuzdan daha fazla olurken, 8 tanesinin ise daha düşük puan aldıkları belirlenmiştir. İncelenen genotiplere ait SÇKM oranları ile tat puanları arasında belirgin bir ilişki bulunmamıştır. Örneğin en yüksek tat puanını alan M2/C kombinasyonunun, SÇKM değeri yönünden orta sırada yer aldığı görülmüştür. Bu durum, SÇKM değerinin tat kalitesinin oluşmasında tek başına yeterli bir kriter olmadığını göstermektedir. Karpuzun tadı üzerine aşılamanın etkisinin incelendiği birçok araştırmada; tadın kullanılan anaca bağlı olarak değişkenlik gösterdiği belirlenmiştir (Yamasaki ve ark., 1994; Atasayar ve ark., 2005; Karaca ve ark., 2012; Oluk ve ark., 2012, Huang ve ark., 2016; Özdemir ve ark., 2016). Ülkemizde aşılı karpuzların tatsız olduğu ve kabak aroması içerdiği şeklinde gerek basın ve gerekse toplumda yaygın bir söylenti mevcuttur. Davis ve ark. (2008a), tat kalitesinin birçok parametreye bağlı olduğunu ve sebzelerde aşılama ile tat kalitesinin pozitif veya negatif yönde etkilenebileceğini ya da hiç etkilenmeyeceğini belirtmiştir. Panelistlerden bazıları; tat yönünden en düşük puanların verildiği $\mathrm{K} 6 / \mathrm{C}$ ve $\mathrm{M} 7 / \mathrm{C}$ kombinasyonlarında, aynı zamanda, hafif derecede kabak kokusuna rastlamışlardır (Çizelge 3). Diğer, 10 anaç/kalem kombinasyonunda ise herhangi bir kabak kokusu varlığı tespit edilmemiştir. Aşılı karpuzlarda meyvenin boyuna kesitinin orta kısmına doğru değişen düzeylerde lif oluşumları görülebilmektedir. Panelistlerden karpuz meyvelerinde liflilik oluşumu hakkında değerlendirme yapmaları da istenmiştir. B1/C, $\mathrm{M} 2 / \mathrm{C}, \mathrm{M} 6 / \mathrm{C}$ ve aşısız karpuz genotiplerinde herhangi bir liflilik durumu bulunmamıştır. Ancak incelenen anaç/kalem kombinasyonlarının büyük bir kısmında hafif derecede lifli yapının ( 9 adet) olduğu saptanmıştır. Panelistler tarafindan M7/C kombinasyonunda ise belirgin bir lifli yapının varlığı gözlenmiştir. Duyusal analiz test sonuçları birlikte değerlendirildiğinde; B1 ve M2 genotiplerine aşılı karpuzlara ait meyvelerin hem tat puanlarının yüksek olması ve hem de lifli yap1 oluşturmamaları nedeniyle daha fazla öne çıktıkları tespit edilmiştir.

Görsel olarak yapmış olduğumuz incelemelerde, meyve et rengi yönünden kombinasyonlar arasında belirgin bir farklılık tespit edilememiştir. Ancak renk 
bileşenlerini daha detaylı ortaya koyan sayısal renk parametreleri yönünden, farklı anaçların karpuzda meyve eti rengini istatistiksel olarak önemli seviyede etkilediği belirlenmiştir (Çizelge 4). Aşı kombinasyonları arasında; $\mathrm{M} 5 / \mathrm{C}, \mathrm{K} 6 / \mathrm{C}$ ve B1/C sirasiyla; 37.42, 34.63 ve 34.27 "L" değerleri ile diğer kombinasyonlardan daha parlak oldukları saptanmıştır. Aşısız karpuza göre (L: 33.13), incelenen anaçların altısında meyve et rengindeki parlaklık azalırken, yedi tanesinde ise arttırıcı yönde olumlu etkide bulunmuştur. "a" değeri yönünden de incelenen kombinasyonlar arasında istatistiksel olarak önemli düzeyle farklılıkların olduğu belirlenmiştir. M6/C kombinasyonu en yüksek (30.64), K11/C ise en düşük "a" değerine (24.28) sahip olmuştur. Fekete ve ark. (2015) ve Soteriou ve ark. (2017), anaçların karpuzun meyve etinin "a" değerini arttırdığını bildirmiş̧lerdir. Araştırmada "b" değerleri, 14.06 (K11/C) ve 19.45 (M7/C) arasinda ve istatistiksel olarak önemli düzeyde farklılık göstermiştir. Anaçlara göre chroma değerleri, 28.07 (K11/C) ve 36.21 (M6/C) arasında değişim göstermiştir (Çizelge 4). Araştırma sonuçları aşılamanın, meyve eti doygunluğunu arttırdığını göstermiştir. Fekete ve ark. (2015) ve Soteriou ve ark. (2017) aş11 karpuzlarda aşısıza göre meyve eti renk doygunluğu değerinde artışlar olduğunu bildirmişlerdir. Özdemir ve ark. (2016) ve Alan ve ark. (2017) ise karpuzda renk doygunluk değerinin kullanılan anaca bağlı olarak değiştiğini belirtmişlerdir.

Kombinasyonlar arasında hue ${ }^{\circ}$ renk açısı da önemli derecede değişkenlik göstermiştir. Hue ${ }^{\circ}$ renk açısıının düşük olması, meyvede kırmızı rengin daha iyi görünmesine sebep olmaktadır. Bu bakımdan; M6/C, $\mathrm{B} 1 / \mathrm{C}, \mathrm{M} 3 / \mathrm{C}$ ve $\mathrm{M} 2 / \mathrm{C}$ kombinasyonlarının diğerlerinden daha yoğun bir kırmızı renk tonuna sahip oldukları tespit edilmiştir (Çizelge 4). Birçok araştırma bulgusu, sebzelerde aşlamanın meyve et rengini etkilediğini göstermiştir (Lee, 1994; Davis ve ark., 2008a; Davis ve ark., 2008b). Ayrıca aş1lı karpuzda meyve et rengine ait hue değerlerinin, anaca bağlı olarak değişkenlik gösterdiği de birçok çalışma sonucunda ortaya konulmuştur (Davis ve Perkins-Veazie, 2005; Karaca ve ark., 2012; Özdemir ve ark.,2016; Alan ve ark., 2017). Çalışmada aşısız karpuz ile farklı anaçlara aşılanan karpuz meyvelerine ait uçucu aroma bileşikleri analizi sonucunda, 48 adet aromatik bileşiğin olduğu tespit edilmiştir. Kütüphane tarama yazılımının sinonim olarak tespit ettiği bileşikler birleştirilerek verilmiştir. Ayrıca yorumlamanın daha kolay yapılabilmesi için yapısal olarak birbirine çok yakın olan bileşikler de birleştirilmiştir. İncelenen aşı kombinasyonlarına ait meyvelerdeki aromatik bileşiklerin ortalama \%48.0'inin aldehit, \% 31.9'unun alkol, \% 5.5'inin keton, \% 2.9 'unun fenol ve geriye kalan \%11.7'inin ise diğer bileşiklerden oluştuğu belirlenmiştir (Çizelge 5). İncelenen kombinasyonlarda, en çok (E,Z)-2,6nonadienal, (Z)-6-nonen-1-ol ve (Z,Z)-3,6-nonadien-1-ol bileşikleri tespit edilmiştir. Araştırma bulguları, önceki yıllarda elde edilen araştırma sonuçları ile benzerlik göstermektedir (Yajima ve ark., 1985; Beaulieu ve Lea, 2006; Saftner ve ark., 2007; Genthner, 2010; Fredes ve ark., 2017). Aş1 kombinasyonlarından hasat edilen meyvelerde bulunan (E,Z)-2,6-nonadienal, toplam bileşiklerin \%31.1'ini kapsayarak en fazla içeriğe sahip aldehit olarak tespit edilmiştir. (E,Z)-2,6-nonadienal, hıyar kokusu ile özdeşleştirilmiş bir bileşiktir (Buescher ve Buescher, 2001).

Çizelge 4. Aşılı ve aşısız karpuzlarda sayısal meyve eti renk değerleri

\begin{tabular}{|c|c|c|c|c|c|c|}
\hline Kombinasyonlar & $\mathrm{L}$ & 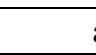 & & $\mathrm{b}$ & $\mathrm{C}^{*}$ & $\mathrm{~h}^{\circ}$ \\
\hline $\mathrm{B} 1 / \mathrm{C}$ & $34.27 \mathrm{~b}$ & 28.62 & $\mathrm{ab}$ & $18.64 \mathrm{ab}$ & $34.19 \mathrm{a}-\mathrm{c}$ & $30.48 \mathrm{~d}$ \\
\hline $\mathrm{K} 6 / \mathrm{C}$ & $34.63 \mathrm{~b}$ & 28.91 & $\mathrm{ab}$ & $17.94 \mathrm{a}-\mathrm{c}$ & $34.05 \mathrm{a}-\mathrm{c}$ & 31.69 b-d \\
\hline K9/C & $32.48 \mathrm{~cd}$ & 27.17 & b-d & $18.17 \mathrm{a}-\mathrm{c}$ & $32.69 \mathrm{a}-\mathrm{d}$ & $33.55 \mathrm{bc}$ \\
\hline $\mathrm{K} 10 / \mathrm{C}$ & $33.68 \mathrm{bc}$ & 25.21 & $\mathrm{~cd}$ & $15.59 \mathrm{~cd}$ & $29.66 \mathrm{de}$ & $32.93 \mathrm{bc}$ \\
\hline $\mathrm{K} 11 / \mathrm{C}$ & $32.49 \mathrm{~cd}$ & 24.28 & $\mathrm{~d}$ & $14.06 \mathrm{~d}$ & $28.07 \mathrm{e}$ & $33.57 \mathrm{bc}$ \\
\hline $\mathrm{M} 2 / \mathrm{C}$ & $33.68 \mathrm{bc}$ & 28.85 & $\mathrm{ab}$ & $17.60 \mathrm{a}-\mathrm{c}$ & $33.80 \mathrm{a}-\mathrm{c}$ & $31.46 \mathrm{~cd}$ \\
\hline $\mathrm{M} 3 / \mathrm{C}$ & $32.63 \mathrm{~b}-\mathrm{d}$ & 29.71 & $\mathrm{ab}$ & $18.06 \mathrm{a}-\mathrm{c}$ & 34.73 a-c & $31.27 \mathrm{~cd}$ \\
\hline $\mathrm{M} 5 / \mathrm{C}$ & $37.42 \mathrm{a}$ & 29.60 & $a b$ & $18.82 \mathrm{ab}$ & $35.10 \mathrm{ab}$ & $32.23 \mathrm{~b}-\mathrm{d}$ \\
\hline $\mathrm{M} 6 / \mathrm{C}$ & $33.27 \mathrm{bc}$ & 30.64 & $\mathrm{a}$ & $19.35 \mathrm{a}$ & $36.21 \mathrm{a}$ & $29.99 \mathrm{~d}$ \\
\hline $\mathrm{M} 7 / \mathrm{C}$ & $31.83 \mathrm{e}$ & 27.95 & $a-c$ & $19.45 \mathrm{a}$ & $34.08 \mathrm{a}-\mathrm{c}$ & $32.29 \mathrm{~b}-\mathrm{d}$ \\
\hline Argentario/C & $32.98 \mathrm{bc}$ & 26.55 & $b-d$ & $15.65 \mathrm{~cd}$ & $30.83 \mathrm{~cd}$ & $34.77 \quad \mathrm{a}$ \\
\hline Obez/C & $32.78 \mathrm{~b}-\mathrm{d}$ & 27.54 & $a-d$ & $17.36 \mathrm{bc}$ & 32.58 b-d & $32.05 \mathrm{~b}-\mathrm{d}$ \\
\hline Shintosa/C & $31.87 \mathrm{e}$ & 28.47 & $a-c$ & $18.80 \mathrm{ab}$ & $34.15 \mathrm{a}-\mathrm{c}$ & $31.64 \mathrm{~b}-\mathrm{d}$ \\
\hline $\mathrm{C}$ & $33.13 \mathrm{bc}$ & 27.57 & $\mathrm{a}-\mathrm{d}$ & $17.22 \mathrm{bc}$ & $32.52 \mathrm{~b}-\mathrm{d}$ & $31.99 \mathrm{~b}-\mathrm{d}$ \\
\hline$P$ & $* *$ & \multicolumn{2}{|c|}{$*$} & $*$ & $*$ & $*$ \\
\hline $\mathrm{CV}(\%)$ & 5.76 & \multicolumn{2}{|c|}{7.10} & 9.24 & 7.35 & 6.97 \\
\hline
\end{tabular}

B: Bal kabağı, K: Kestane Kabağı, M: Türler arası melez (C. maxima $\times$ C. moschata), C: Aşısız Crisby $\mathrm{F}_{1}$, **: P>0.01; *: P>0.05 
Çizelge 5. Farklı kombinasyonlara ait karpuzlarda tespit edilen aromatik bileşiklerin oransal dağılımı (\%)

\begin{tabular}{|c|c|c|c|c|c|c|c|c|c|c|c|c|c|c|}
\hline & \multicolumn{4}{|c|}{ Keton } & \multicolumn{4}{|c|}{ Alkol } & \multicolumn{4}{|c|}{ Aldehit } & \multirow{2}{*}{$\frac{\text { Fenol }}{10}$} & \multirow{2}{*}{$\frac{\text { Diğerleri }}{\sum}$} \\
\hline & $\Sigma$ & 1 & 2 & 3 & $\Sigma$ & 4 & 5 & 6 & $\Sigma$ & 7 & 8 & 9 & & \\
\hline $\mathrm{B} 1 / \mathrm{C}$ & $6.7 \mathrm{c}$ & $-e$ & $6.7 b$ & $-g$ & $33.2 b-d$ & $20.8 \mathrm{a}$ & $3.2 \mathrm{~h}$ & $9.2 \mathrm{~g}$ & $42.8 b c$ & $12.9 \mathrm{c}$ & -1 & 29.9ef & $2.2 \mathrm{f}$ & 15.1 \\
\hline K6/C & $3.9 \mathrm{~g}$ & $2.3 \mathrm{c}$ & $1.3 \mathrm{i}$ & $0.3 \mathrm{f}$ & $28.4 \mathrm{ef}$ & $18.1 b c$ & $1.2 \mathrm{i}$ & $9.1 \mathrm{~g}$ & $53.8 \mathrm{ab}$ & $15.2 \mathrm{~b}$ & $9.6 \mathrm{c}$ & 29.0e-g & $2.6 \mathrm{e}$ & 6.9 \\
\hline K9/C & $7.1 \mathrm{~b}$ & $7.1 \mathrm{a}$ & $-j$ & $-g$ & $26.8 \mathrm{fg}$ & $3.1 \mathrm{~h}$ & $5.1 \mathrm{f}$ & $18.6 \mathrm{a}$ & $50.9 \mathrm{c}-\mathrm{e}$ & $14.8 \mathrm{~b}$ & $1.0 \mathrm{k}$ & $35.1 \mathrm{bc}$ & $4.2 \mathrm{~b}$ & 10.5 \\
\hline $\mathrm{K} 10 / \mathrm{C}$ & $5.0 \mathrm{ef}$ & $-e$ & $5.0 \mathrm{de}$ & $-g$ & $29.1 \mathrm{ef}$ & $19.2 b$ & $-j$ & $9.9 \mathrm{fg}$ & $47.8 \mathrm{~cd}$ & $16.7 \mathrm{a}$ & $1.6 \mathrm{j}$ & $29.5 \mathrm{e}-\mathrm{g}$ & $2.9 \mathrm{~d}$ & 11.8 \\
\hline $\mathrm{K} 11 / \mathrm{C}$ & $4.6 f$ & $0.7 \mathrm{~d}$ & $3.9 \mathrm{gh}$ & $-g$ & $33.9 b c$ & $16.6 \mathrm{~d}$ & $-j$ & $17.3 \mathrm{~b}$ & $44.6 \mathrm{fg}$ & $11.9 \mathrm{c}$ & -1 & $32.7 \mathrm{~cd}$ & $3.0 \mathrm{~d}$ & 14.0 \\
\hline $\mathrm{M} 2 / \mathrm{C}$ & $8.1 \mathrm{a}$ & $-e$ & $7.7 \mathrm{a}$ & $0.4 \mathrm{e}$ & $34.2 \mathrm{bc}$ & $17.4 \mathrm{~cd}$ & $6.4 d$ & $10.4 \mathrm{ef}$ & $43.0 \mathrm{~g}$ & $6.0 \mathrm{f}$ & $11.9 \mathrm{a}$ & $25.1 \mathrm{i}$ & $9.4 \mathrm{a}$ & 5.3 \\
\hline $\mathrm{M} 3 / \mathrm{C}$ & $7.6 \mathrm{~b}$ & $-e$ & $6.0 \mathrm{c}$ & $1.6 \mathrm{a}$ & $34.0 \mathrm{bc}$ & $11.9 \mathrm{fg}$ & $10.6 \mathrm{~b}$ & $11.5 \mathrm{de}$ & $41.4 \mathrm{e}-\mathrm{g}$ & $7.8 \mathrm{e}$ & $2.3 \mathrm{i}$ & $31.3 \mathrm{de}$ & $1.7 \mathrm{~g}$ & 10.1 \\
\hline $\mathrm{M} 5 / \mathrm{C}$ & $4.9 f$ & $-e$ & $3.6 \mathrm{~h}$ & $1.3 b$ & $30.8 \mathrm{de}$ & 13.0ef & $7.9 \mathrm{c}$ & $9.9 \mathrm{fg}$ & $53.4 \mathrm{a}$ & $7.6 \mathrm{e}$ & $8.9 \mathrm{~d}$ & $36.9 b$ & $1.0 \mathrm{i}$ & 4.4 \\
\hline M6/C & $4.7 f$ & $-e$ & $4.7 \mathrm{ef}$ & $-g$ & $25.5 \mathrm{~g}$ & $4.0 \mathrm{~h}$ & $3.0 \mathrm{~h}$ & $18.5 \mathrm{a}$ & $52.8 \mathrm{c}$ & $10.0 \mathrm{~d}$ & $3.0 \mathrm{~h}$ & $39.8 \mathrm{a}$ & $1.3 \mathrm{~h}$ & 15.8 \\
\hline $\mathrm{M} 7 / \mathrm{C}$ & $4.1 \mathrm{~g}$ & $-e$ & $4.1 \mathrm{~g}$ & $-g$ & $29.7 \mathrm{e}$ & $16.8 \mathrm{~d}$ & $3.9 \mathrm{~g}$ & $9.0 \mathrm{~g}$ & $48.9 \mathrm{ab}$ & $12.3 \mathrm{c}$ & $7.7 \mathrm{e}$ & $28.9 \mathrm{e}-\mathrm{h}$ & $2.1 \mathrm{f}$ & 6.4 \\
\hline Argentario/C & $5.5 \mathrm{~d}$ & $5.2 b$ & $0.3 \mathrm{j}$ & $-g$ & $38.6 \mathrm{a}$ & $16.8 \mathrm{~d}$ & $5.8 \mathrm{e}$ & $16.0 \mathrm{c}$ & $46.5 \mathrm{fg}$ & $9.1 \mathrm{~d}$ & $11.1 \mathrm{~b}$ & 26.3hi & $2.4 \mathrm{ef}$ & 5.4 \\
\hline Obez/C & $5.1 \mathrm{~d}-\mathrm{f}$ & $-e$ & $5.1 \mathrm{~d}$ & $-g$ & $35.3 \mathrm{~b}$ & $10.8 \mathrm{~g}$ & $12.8 \mathrm{a}$ & $11.7 \mathrm{~d}$ & $51.1 \mathrm{~cd}$ & $16.4 \mathrm{a}$ & $6.2 \mathrm{~g}$ & $28.5 f-h$ & $2.6 \mathrm{e}$ & 9.7 \\
\hline Shintosa/C & $5.4 \mathrm{de}$ & $-e$ & $4.3 \mathrm{fg}$ & $1.1 \mathrm{c}$ & $32.4 \mathrm{~cd}$ & $14.0 \mathrm{e}$ & $6.3 \mathrm{de}$ & $12.1 \mathrm{~d}$ & $51.4 \mathrm{~cd}$ & $9.1 \mathrm{~d}$ & 7.0f & $35.3 b$ & $1.2 \mathrm{hi}$ & 7.0 \\
\hline $\mathrm{C}$ & $4.7 \mathrm{f}$ & $-\mathrm{e}$ & $4.1 \mathrm{~g}$ & $0.6 \mathrm{~d}$ & $35.0 \mathrm{bc}$ & $13.7 \mathrm{e}$ & $5.2 \mathrm{f}$ & $16.1 \mathrm{c}$ & 43.6d-f & $9.9 \mathrm{~d}$ & $6.7 \mathrm{fg}$ & $27.0 \mathrm{~g}-\mathrm{i}$ & $3.5 \mathrm{c}$ & 8.6 \\
\hline $\mathrm{P}$ & $* *$ & $* *$ & $* *$ & $* *$ & $* *$ & $* *$ & $* *$ & $* *$ & $* *$ & $* *$ & $* *$ & $* *$ & $* *$ & \\
\hline $\mathrm{CV}(\%)$ & 5.0 & 11.0 & 5.7 & 8.6 & 5.0 & 5.3 & 6.1 & 5.2 & 5.0 & 5.3 & 6.2 & 7.8 & 6.1 & \\
\hline
\end{tabular}

(1): 3.5.5-trimethyl 2-cyclohexen-1-one, (2): Geranyl acetone, (3): 3-buten-2-one, (4): (Z)-6-nonen-1-ol, (5): 1-nonanol, (6): (Z,Z)3,6-nonadien-1-ol, (7): 2-nonenal, (8): Nonanal, (9): (E,Z)-2,6-nonadienal, (10): 2.6 bis (1.1dimethylethyl)-4-methyl phenol, B: Bal kabağı, K: Kestane Kabağı, M: Türler arası melez (C. maxima $\times$ C. moschata), C: Aşısız Crisby $\mathrm{F}_{1}$, **: P>0.01

Bu bileşik, aşısız karpuzda \% 27 oranında bulunurken aş11 karpuzlarda \% 25.1 (M2/C) ve \% 39.8 (M6/C) arasında dağılım göstermiştir. Bu yönden $\mathrm{M} 2$ anaç adayı ümitvar bulunmuştur. (Z)-6-nonen-1-ol bileşiği, \% 3.1 ve \% 20.8 arasında dağılış göstererek alkoller arasında içerik yönünden ilk sırada yer almıştır (Çizelge 5). Fredes ve ark. (2017), bu bileşiğin kabak kokusunu arttırdığı ve türler arası melez kabak anacına aşılı kombinasyonlarda daha fazla artış gösterdiğini bildirmiş̧lerdir. Yaptığımız çalışmada bu bileşik oranları, kontrole göre 8 anaçta artış ve 5 anaçta ise azalış göstermiştir. (Z)-6-nonen-1-ol bileşiği yönünden en düşük değer; M6 anacına aşılı karpuzlarda tespit edilmiştir. (Z,Z)-3,6-nonadien-1-ol alkol bileşiği yönünden ise en düşük değerler M7/C (\% 9.0), K6/C (\% 9.1) ve B1/C (\% 9.2) en yüksek değerler ise $\mathrm{K} 9 / \mathrm{C} \quad\left(\begin{array}{ll}\% & 18.6)\end{array}\right)$ ve $\mathrm{M} 6 / \mathrm{C} \quad\left(\begin{array}{ll}\% & 18.5\end{array}\right)$ kombinasyonlarında tespit edilmiştir.

Genthner (2010), (Z,Z)-3,6-nonadien-1-ol aromatik bileşiği ile karpuz kokusu arasında pozitif korelasyon olduğunu bildirmiştir. Aşılı kombinasyonlar, aşısız kontrol çeşide göre bu bileşik yönünden $\% 28$ daha az içeriğe sahip olmuştur (Çizelge 5). Guler ve ark. (2014), su kabağına aşı1ı karpuz kombinasyonlarında bu bileşikte düşüş olduğunu saptamışlardır. Ancak çalışmamızdaki anaç kombinasyonlar arasında (Z,Z)-3,6-nonadien-1-ol yönünden önemli seviyede varyasyon olduğu bulunmuştur. M6/C kombinasyonunun, (Z,Z)-3,6nonadien-1-ol içeriği aşısız karpuzdan daha yüksek olarak belirlenmiştir. Karpuz aroması yüksek çıkan bu anacın, 1slah programlarında kullanılması planlanmaktadır.

Araştırma bulguları, aşılamanın aromatik bileşiklerin miktarı üzerine etkisinin önemli olduğunu göstermiştir.
Ancak yapılan diğer çalışmalarda olduğu gibi, bu çalışmada da aromatik bileşiklerin oranları kıyaslandığında oldukça değişken seviyelerde oldukları tespit edilmiştir. $\mathrm{Bu}$ durum, aromatik bileşik ölçümlerinin çok hassas olması, aroma içeriğinin çevre koşullarından ve uygulanan yetiştirme tekniklerinden etkilenmesi gibi nedenlerden dolay verilerin stabil olmamasından kaynaklanmış olabilir. Aroma bileşiklerinin, meyve tadını etkileyen kriterlerle ilişkisi yada tat üzerine etkisinin tam olarak ortaya konulması halen mümkün görünmemektedir. Çünkü, tespit edilen aromatik bileşik sayısı ile bu bileşiklerin miktarları, farklı anaç/kalem kombinasyonlarında çok farklı sayı ve oranlarda bulunmuştur. Üstelik tat; aroma bileşikleri, karotenoidler, şekerler ve ekolojik koşulların birbirleriyle olan interaksiyonları sonucu oluşmaktadır. $\mathrm{Bu}$ durumun daha net olarak ortaya çıkarılabilmesi için; gelecekte daha az genetik materyal kullanılarak, daha spesifik ve teknolojik çalışmaların yapılmasına ihtiyaç bulunmaktadır.

\section{Sonuç}

Araştırma sonucunda karpuzda anaç kullanımının meyve kalitesini büyük oranda değiştirdiği belirlenmiş̧ir. Genel olarak meyve eti sertliği, kırmızı et rengi yoğunluğu ve SÇKM değerlerinde anaç kullanımı ile artışların olduğu tespit edilmiştir. Aşılı karpuz meyveleri, daha kalın kabuklu olarak belirlenmiştir. Yine anacın meyve kuru maddesi ve meyve şeklini değiştirmediği saptanmıştır. C vitamini, likopen, tat skala puanları ve aroma bileşikleri ise kullanılan anaca bağlı olarak artmış yada azalmıştır. Meyve eti sert, SÇKM ve 
likopen miktarı yüksek, lifsiz yapıll, kabak kokusu az ve karpuz kokusu fazla uçucu aromatik bileşikleri içeren karpuz meyvesinin elde edilmesini sağlayan M6 anac1, meyve kalitesini arttıran en iyi yerli anaç adayı olarak tespit edilmiştir. Ayrıca doktora çalışması kapsamında yürütülmüş olan verim denemesi sonuçlarına göre; en yüksek verim değerine ulaşan M2 anacı da en yüksek tat puanını almış, meyve eti sert ve yoğun kırmızı renge sahip olmuştur. Kalite yönünden ön plana çıkan M6 ve M2 türler arası melez anaç adaylarının farklı lokasyonlarda ve farklı karpuz çeşidi kombinasyonlarıyla verim ve kalite denemeleri sonucunda tescil aşamasına getirilerek ilk yerli anaçların geliştirilmesi hedeflenmektedir.

\section{Teşekkür}

$\mathrm{Bu}$ çalışma; Ondokuz Mayıs Üniversitesi Bilimsel Araştırma Fonu (PYO.ZRT.1901.09.015) ve Tarımsal Araştırmalar ve Politikalar Genel Müdürlüğü (TAGEMBS-2009-29) tarafından desteklenmiştir.

\section{Kaynaklar}

Alan, Ö., Özdemir, N., Günen, Y., 2007. Effect of grafting on watermelon plant growth, yield and quality, Journal of Agronomy, 6 (2): 362-365.

Alan, O., Sen, F., Duzyaman, E., 2017. The effectiveness of growth cycles on improving fruit quality for grafted watermelon combinations. Food Science and Technology, DDOI: http://dx.doi.org/10.1590/1678-457X.20817 (Erişim Tarihi: 15 Aralık 2017).

Alexopoulos, A.A., Kondylis, A., Passam, H.C., 2007. Fruit yield and quality of watermelon in relation to grafting. Journal of Food, Agriculture \& Environment, 5 (1):178-179.

Arslan, Ö., 2010. Crisby karpuz çeşidinde aşılı üretimin derim sonrası kalite ve raf ömrüne etkileri. Yüksek Lisans Tezi, Mustafa Kemal Üniversitesi, Fen Bilimleri Enstitüsü, 73 s., Hatay.

Atasayar, A., Polat, E., Onus, N., 2005. Türkiye'de aş11 karpuz fidesi kullanımı üzerine genel değerlendirme, Türkiye II. Tohumculuk Kongresi, 51-58, 9-11 Kasım, Adana.

Balkaya, A., Özcan, M., 1997. Sebzelerde kalite ve kaliteyi etkileyen faktörler. Bahçe Ürünlerinde Muhafaza ve Pazarlama Sempozyumu. 295-311. 21-24 Ekim, Yalova.

Balkaya, A., Kurtar, E.S., Yanmaz, R., Özbakır, M., 2008. Karadeniz Bölgesinde kışlık kabak türlerinde kestane kabağ (Cucurbita maxima Duchesne) ve balkabağı (Cucurbita moschata Duchesne) gen kaynaklarının toplanması, karakterizasyonu ve değerlendirilmesi. TUBITAK TOVAG. Proje No: 1040144, $172 \mathrm{~s}$.

Balkaya, A., 2013. Aş1lı karpuz yetiştiriciliğinde meyve kalitesini etkileyen faktörler. Türkiye Tohumcular Birliği Dergisi, 2: 6-9.
Bang, H., Davis, A., Kim, S., Leskovar, D., King, S.R., 2010. Flesh color inheritance and gene interactions among canary yellow, pale yellow and red watermelon. Journal of the American Society for Horticultural Science, 135 (4), 362-368.

Barua, A.B., 2001. Improved normal-phase and reversedphase gradient high-performance liquid chromatography procedures for the analysis of retinoids and carotenoids in human serum, plant and animal tissues. Journal of Chromatography A, 936: 71-82.

Beaulieu, J.C., Lea, J.M., 2006. Characterization and semiquantitative analysis of volatiles in seedless watermelon varieties using solid-phase microextraction. Journal of Agricultural and Food Chemistry, 54 (20), : 7789-7793.

Bigdelo, M., Hassandokht, M. R., Rouphael, Y., Colla, G., Soltani, F., Salehi, R., 2017. Evaluation of bitter apple (Citrullus colocynthis (L.) Schrad) as potential rootstock for watermelon. Australian Journal of Crop Science, 11(6): 727.

Bozan, B., Tunalıer, Z., Koşar, M., Altıntaş, A., Başer, K.H.C., 1996. Türkiye piyasasında bulunan kuşburnu ürünlerinde $\mathrm{C}$ vitamini tayini, Editör: Coşkun, M., X. Bitkisel İlaç Hammaddeleri Toplantıs1, 258-266, 22-24 May1s, Ankara.

Bruton, B.D., Fish, W.W., Roberts, W., Popham, T.W., 2009. The influence of rootstock selection on fruit quality attributes of watermelon. The Open Food Science Journal, 3: 15-34.

Buescher, R. H., Buescher, R.W., 2001. Production and stability of (E, Z)-2, 6-Nonadienal, the major flavor volatile of cucumbers. Journal of food science, 66(2): 357-361.

Colla, G., Roupahel, Y., Carderelli, M., 2006. Effect of salinity on yield, fruit quality, leaf gas exchange, and mineral composition of grafted watermelon plants. HortScience, 41 (3): 622-627.

Colla, G., Rouphael, Y., Cardarelli, M., Temperini, O., Fanasca, S., Pierandrei, F., Salerno, A., Rea, E., 2007. Salt tolerance and mineral relations for grafted and ungrafted watermelon plants grown in NFT. Proceeding VIIIth IS on Protected Cultivation in Mild Winter Climates. Acta Horticulturae, 747: 241-248.

Collins, J.K., Perkins-Veazie, P., 2006. Lycopene: from plants to humans. HortScience, 41 (5), 1135-1144.

Çandır, E., Yetişir, H., Karaca, F., Üstün, D., 2013. Phytochemical characteristics of grafted watermelon on different bottle gourds (Lagenaria siceraria) collected from Mediterranean region of Turkey. Turkish Journal of Agriculture and Forestry, 37(4): 443-456.

Davis, A.R., Perkins-Veazie, P., 2005. Rootstock effects on plant vigor and watermelon fruit quality. Cucurbit Genetics Cooperative Report, 29: 39-42.

Davis, A. R., Perkins-Veazie, P., Hassell, R., Levi, A., King, S. R., Zhang, X., 2008a. Grafting effects on vegetable quality. HortScience, 43(6): 1670-1672. 
Davis, A.R., Perkins-Veazie, P., Sakata, Y., LópezGalarza, S., Maroto, J.V., Lee, S.G., Huh, Y.C., Sun, Z., Miguel, A., King, S.R., Cohen, R., Lee., J.M., 2008b. Cucurbit grafting. Critical Reviews in Plant Sciences, 27: 50-74.

Edelstein, M., Tyutyunik, J., Fallik, E., Meir, A., Tadmor, Y., Cohen, R., 2014. Horticultural evaluation of exotic watermelon germplasm as potential rootstocks. Scientia Horticulturae, 165: 196-202.

Fekete, D., Stéger-Máté, M., Bőhm, V., Balázs, G., Kappel, N., 2015. Lycopene and flesh colour differences in grafted and non-grafted watermelon. Acta Universitatis Sapientiae, Alimentaria, 8(1): 111-117.

Fita, A., Pico, B., Roig, C., Nuez, F. 2007. Performance of Cucumis melo ssp. agrestis as a rootstock for melon. The Journal of Horticultural Science and Biotechnology, 82(2): 184-190.

Fredes, A., Roselló, S., Beltrán, J., Cebolla-Cornejo, J., Pérez-de-Castro, A., Gisbert, C., Picó, M.B., 2017. Fruit quality assessment of watermelons grafted onto citron melon rootstock. Journal of the Science of Food and Agriculture, 97(5): 1646-1655.

Genthner, E.R., 2010. Identification of key odorants in fresh-cut watermelon aroma and structure-odor relationships of Cis,Cis-3,6-nonadienal and ester analogs with $\mathrm{Cis}, \mathrm{Cis}-3,6-$ nonadiene, Cis-3-nonene and Cis-6-nonene backbone structures. Master of Science, Food Science and Human Nutrition in the Graduate College, University of Illinois, p.105, Urbana-Champaign.

Guler, Z., Candir, E., Yetisir, H., Karaca, F., Solmaz, I., 2014. Volatile organic compounds in watermelon (Citrullus lanatus) grafted onto 21 local and two commercial bottle gourd (Lagenaria siceraria) rootstocks. The Journal of Horticultural Science and Biotechnology, 89(4): 448-452.

Gusmini, G., Wehner, T.C., 2005a. Foundations of yield improvement in watermelon. Crop Science, 45: 141-146.

Gusmini, G., Wehner, T.C., 2005b. Review of watermelon genetics for plant breeders. Cucurbit Genetics Cooperative Report, 28-29: 52-61.

Huang, Y., Tang, R., Cao, Q., Bie, Z., 2009. Improving the fruit yield and quality of cucumber by grafting onto the salt tolerant rootstock under $\mathrm{NaCl}$ stress. Scientia Horticulturae, 122(1): 26-31.

Huang, Y., Zhao, L., Kong, Q., Cheng, F., Niu, M., Xie, J., Nawaz, A.M., Bie, Z., 2016. Comprehensive mineral nutrition analysis of watermelon grafted onto two different rootstocks. Horticultural Plant Journal, 2(2): 105-113.

Huitrón, M.V., Diaz, M., Diánez, F., Camacho, F., 2007. The effect of various rootstocks on triploid watermelon yield and quality. Journal of Food, Agriculture \& Environment, 5 (3/4): 344-348.

Huitrón-Ramírez, M.V., Ricardez-Salinas, M., Camacho, F., 2009. Influence of grafted watermelon plant density on yield and quality in soil infested with melon necrotic spot virus. HortScience, 44 (7): 1838-1841.

Kafkas, E., 2004. Bazı çilek genotiplerinde aroma bileşiklerinin tayini ve aroma bileşikleri ile bazı meyve kalite kriterleri arasında ilişkiler. Doktora Tezi, Çukurova Üniversitesi, Fen Bilimleri Enstitüsü, s. 310, Adana.

Karaağaç, O., 2013. Karadeniz Bölgesinden Toplanan Kestane Kabağı ( $C$. maxima Duchesne) ve Bal Kabağı (C. moschata Duchesne) Genotiplerinin Karpuza Anaçlık Potansiyellerinin Belirlenmesi, (Doktora Tezi), Ondokuz Mayıs Üniversitesi, Fen Bilimleri Enstitüsü, s. 238, Samsun.

Karaağaç, O., Balkaya, A., 2013. Interspecific hybridization and hybrid seed yield of winter squash (Cucurbita maxima Duch.) and pumpkin (Cucurbita moschata Duch.) lines for rootstock breeding. Scientia Horticulturae, 149: 9-12.

Karaağaç, O., Balkaya, A., 2016. Kabak anaç 1slah programı ile geliştirilen yerli kabak anaç adaylarının hipokotil özellikleri ve aşılı karpuz fidesi üretiminde kullanılabilirlik durumlarının incelenmesi. 11. Sebze Tarım Sempozyumu, 11-13 Ekim, Ordu.

Karaca, F., Yetişir, H., Solmaz, I., Candir, E., Kurt, Ş., Sari, N., Güler, Z., 2012. Rootstock potential of Turkish Lagenaria siceraria germplasm for watermelon: plant growth, yield and quality. Turkish Journal of Agriculture and Forestry, 36(2): 167-177.

Kyriacou, M.C., Soteriou, G.A., Rouphael, Y., Siomos, A.S., Gerasopoulos, D., 2016. Configuration of watermelon fruit quality in response to rootstockmediated harvest maturity and postharvest storage. Journal of the Science of Food and Agriculture, 96(7): 2400-2409.

Lee, J.M., 1994. Cultivation of grafted vegetables I. Current status, grafting methods, and benefits, HortScience, 29 (4): 235-244.

Leonardi, C., Kyriacou, M., Gisbert, C., Oztekin, G.B., Mourão, I., Rouphael, Y., 2017. Quality of grafted vegetables. In: Vegetable Grafting: Principles and Practices. Eds. G. Colla, F. Pérez-Alfocea and D. Schwarz. CAB International, Oxfordshire, UK, 216-244.

Leskovar, D.I., Bang, H., Crosby, K.M., Maness, N., Franco, J.A., Perkins-Veazie, P., 2004. Lycopene, carbohydrates, ascorbic acid and yield components of diploid and triploid watermelon cultivars are affected by limited irrigation. Journal of Horticultural Science \& Biotechnology, 79 (1): 75 81.

Lewinsohn, E., Sitrit, S., Bar, E., Azulay, Y., Meir, A., Zamir, D., Tadmor, Y., 2005. Carotenoid pigmentation affects the volatile composition of tomato and watermelon fruits, as revealed by 
comparative genetic analyses. Journal of Agricultural and Food Chemistry, 53: 3142-3148.

Li, H.,Wang, M.,, Yu, X.,, Wang, H., Gao, J., Yu, C., 2006. Effect of different scions/rootstocks on quality of cucumber fruits in greenhouse. Scientia Agricultura Sinica, 39 (8):1611-1616.

Liu, Q., Zhao, X., Brecht, J. K., Sims, C.A., Sanchez, T., Dufault, N.S., 2017. Fruit quality of seedless watermelon grafted onto squash rootstocks under different production systems. Journal of the Science of Food and Agriculture. DOI 10.1002/jsfa.8338, (Erişim Tarihi: 15 Aralık 2017)

Mélo, E.A., Lima, V.L.A.G., Maciel, M.I.S., Caetano A.C.S., Leal, F.L.L., 2006. Polyphenol, ascorbic acid and total carotenoid contents in common fruits and vegetables. Brazilian Journal Food Technology, 9 (2),: 89-94.

Miguel, A., Maroto, J.V., San Bautista, A., Baixauli, C., Cebolla, V., Pascual, B., Lopez, S., Guardiola, J.L., 2004. The grafting of triploid watermelon is an advantageous alternative to soil fumigation by methyl bromide for control of Fusarium wilt. Scientia Horticulturae, 103: 9-17.

Oluk, C.A., Aras, V., Ağçam, E., Akyıldız, A., Sari, N., Göçmen, M., 2012. Investigation on fruit quality of grafted watermelon, Cucurbitaceae 2012, Proceedings of the Xth EUCARPIA meeting on genetics and breeding of Cucurbitaceae, 15-18th October, 361-367, Antalya, Turkey.

Oluk, A.C., Aras, V., Ağçam, E., Akyildiz, A., Sari, N., 2017. Some biochemical characteristics of grafted watermelon. The Horticultural Society of India, 74(1): 71-74.

Özdemir, A.E., Çandır, E., Yetişir, H., Aras, V., Arslan, Ö., Baltaer, Ö., Üstün, D., Ünlü, M., 2016. Effects of rootstocks on storage and shelf life of grafted watermelons. Journal of Applied Botany and Food Quality, 89: 191-201.

Perkins-Veazie, P., Collins, J.K., 2004. Flesh quality and lycopene stability of fresh-cut watermelon. Postharvest Biology and Technology, 31: 159-166.

Perkins-Veazie, P., Collins, J.K., Davis, A.R., Roberts, W., 2006. Carotenoid content of 50 watermelon cultivars. Journal of Agriculture Food Chemistry, 54: 2593-2597.

Petropoulos, S. A., Olympios, C., Ropokis, A., Vlachou, G., Ntatsi, G., Paraskevopoulos, A., Passam, H. C., 2014. Fruit volatiles, quality, and yield of watermelon as affected by grafting. Journal of Agricultural Science and Technology, 16(4): 873$\underline{885}$

Proietti, S., Rouphael, Y., Colla, G., Cardarelli, M., De Agazio, M., Zacchini, M., Rea, E., Moscatello, S., Battistelli, A., 2008. Fruit quality of miniwatermelon as affected by grafting and irrigation regimes. Journal of the Science of Food and Agriculture, 88: 1107-1114.

Qin, Y., Yang, C., Xia, J., He, J., Ma, X., Yang, C., Zheng, Y., Lin, X., He, Z., Huang, Z., Yan, Z.,
2014. Effects of dual/threefold rootstock grafting on the plant growth, yield and quality of watermelon. Not Bot Horti Agrobo, 42(2):495-500.

Roberts, W., Bruton, B., Popham, T., Fish, W., 2005. Improving the quality of fresh-cut watermelon through grafting and rootstock selection. Watermelon Research Group, HortScience, 40 (3),: 871.

Rouphael, Y., Cardarelli, M., Colla, G., 2008. Yield, mineral composition, water relations, and water use efficiency of grafted mini-watermelon plants under deficit irrigation, HortScience, 43 (3): 730-736.

Rouphael, Y., Schwarz, D., Krumbein, A., Colla, G., 2010. Impact of grafting on product quality of fruit vegetables. Scientia Horticulturae, 127(2), 172-179.

Rouphael, Y., Rea, E., Cardarelli, M., Bitterlich, M., Schwarz, D., Colla, G., 2016. Can adverse effects of acidity and aluminum toxicity be alleviated by appropriate rootstock selection in cucumber?. Frontiers in plant science, 7, (1283), 112. Doi 10.3389/fpls.2016.01283.

Saftner, R., Luo, Y., McEvoy, J., Abbott, J. A., Vinyard, B., 2007. Quality characteristics of fresh-cut watermelon slices from non-treated and 1methylcyclopropene and/or ethylene-treated whole fruit. Postharvest Biology and Technology, 44: 7179.

Sakata, Y., Ohara, T., Sugiyama, M., 2007. The history and present state of the grafting of Cucurbitaceous vegetables in Japan. III. International Symposium on Cucurbits, Acta Horticulturae, 731: 159-170.

Saladié, M., Matas, A. J., Isaacson, T., Jenks, M.A., Goodwin, S.M., Niklas, K.J., Xiaolin, R., Labavitch, J.M., Shackel, K.A., Fernie, A.R., Lytovchenko, A., O'Neill, M.A., Watkins, C.B., Rose, J. K.C., 2007. A reevaluation of the key factors that influence tomato fruit softening and integrity. Plant Physiology, 144(2): 1012-1028.

Salam, M.A., Masum, A.S.M.H., Chowdhury, S.S., Dhar, M., Saddeque, M.A., Islam, M.R., 2002. Growth and yield of watermelon as influenced by grafting. J. Biol. Sci, 2(5): 298-299.

Soteriou, G.A., Kyriacou, M.C., 2015. Rootstockmediated effects on watermelon field performance and fruit quality characteristics. International journal of vegetable science, 21(4): 344-362.

Soteriou, G.A., Papayiannis, L.C., Kyriacou, M.C., 2016. Indexing melon physiological decline to fruit quality and vine morphometric parameters. Scientia Horticulturae, 203: 207-215.

Soteriou, G.A., Siomos, A,S., Gerasopoulos, D., Rouphael, Y., Georgiadou, S., Kyriacou, M.C., 2017. Biochemical and histological contributions to textural changes in watermelon fruit modulated by grafting. Food Chemistry, 237:133-140

Shalit, M., Katzir, N., Tadmor, N., Larkov, O., Burger, Y., Shalekhet, N., Lastochkin, E., Ravid, U., Amar, O., Edelstein, M., Karchi, Z., Lewinsohn, E., 2001. Acetyl Co-A: Alcohol acetyl transferase activity 
and aroma formation in ripening melon fruits. Journal of Agricultural Food Chemistry, 49: 794799.

Taylor, M., Bruton, B., Fish, W., Roberts, W. 2006. Cost benefit analyses of using grafted watermelons for disease control and the fresh-cut market. Proceeding Cucurbitaceae, 277-285.

Tlili, I., Hdider, C., Lenucci, M.S., Riadh, I., Jebari, H., Dalessandro, G., 2011. Bioactive compounds and antioxidant activities of different watermelon (Citrullus lanatus (Thunb.) Mansfeld) cultivars a saffected by fruit sampling area. Journal of Food Composition and Analysis, 24 (3): 307-314.

USDA, 2017. Nutrient Food Composition Databases, Available at http://ndb.nal.usda.gov/ndb/foods/list (Erişim tarihi: 15 Aralık 2017).

Wehner, T.C., 2008. Watermelon, Editors: Prohens, J., Nuez, F., Handbook of Plant Breeding; Vegetables I: Asteraceae, Brassicaceae, Chenopodiaceae, and Cucurbitaceae, Springer Science Business LLC, New York, 381-418.
Yajima, I., Sakakibara, H., Ide, J., Yanai, T., Hayashi, K., 1985. Volatile flavor components of watermelon (Citrullus vulgaris). Agricultural Biology and Chemistry, 49: 3145-3150.

Yamasaki, A., Yamashita, M., Furuya, S., 1994. Mineral concentrations and cytokinin activity in the xylem exudate of grafted watermelons as affected by rootstocks and crop load. Journal of the Japanese Society for Horticultural Science, 62(4): 817-826.

Yetişir, H., Sarı, N., 2003. Effect of rootstock on plant growth, yield and quality of watermelon. Au:12691274.

Yetişir, H., 2017. History and current status of grafted vegetables in Turkey. Chronica Horticulturae, 57 (1): 13-18.

Zhu, J., Bie, Z., Xu, R., Tang, M., Pei, Y., 2006. Effects of different rootstocks on the growth yield and quality of cucumber fruits. Journal of Huazhong Agricultural University, 25 (6). 